\title{
STANDARD MOTORCYCLE HELMET USAGE AND ITS EFFECT ON ROAD TRAFFIC SAFETY IN THE TWO MAJOR CITIES OF VIETNAM
}

By Trinh Thuy Anh ${ }^{1}$

The number and severity of road accidents in Vietnam is at alarming rate. From 2003, the Government has tried to improve traffic safety, therefore the number of accident and traumatic brain injury (TBI) and the rate of death reduced suddenly. However, from the end of 2008, even though accident number decreasing, a number of TBI and deaths due to road crash are jumping up. This paper aims to analyze the reason of heavy injuries, TBI and deaths happening increased. The specific surveys were taken to motorcyclists, helmet market, traffic safety agencies and hospital in Hanoi and Ho Chi Minh City. Statistic method, integrated comparison, observation, expert interview survey and brainstorming method have been used in this study to analyze the problem. Then road safety situation, helmet usage, regulation and enforcement were analyzed. Base on these, proposal to improve road safety in the two major cities in Vietnam is going to be discussed.

Keyword: road safety, traumatic brain injury (TBI), traffic accident, road crash.

\section{Fact on Road Traffic Safety in} \section{Vietnam}

From 1993, road traffic accidents had been increasing and traffic safety was a big problem in Vietnam. The number of road accidents has been increasing at alarming rate up to 2002 . From 2003, the Government had tried to keep enforcement then the number was slowing down suddenly. However, traffic safety still is the hot problem in Vietnam. Even though the number of accidents and injuries has been decreasing; the number of fatalities is increasing year by year. Figure 1 show this data.

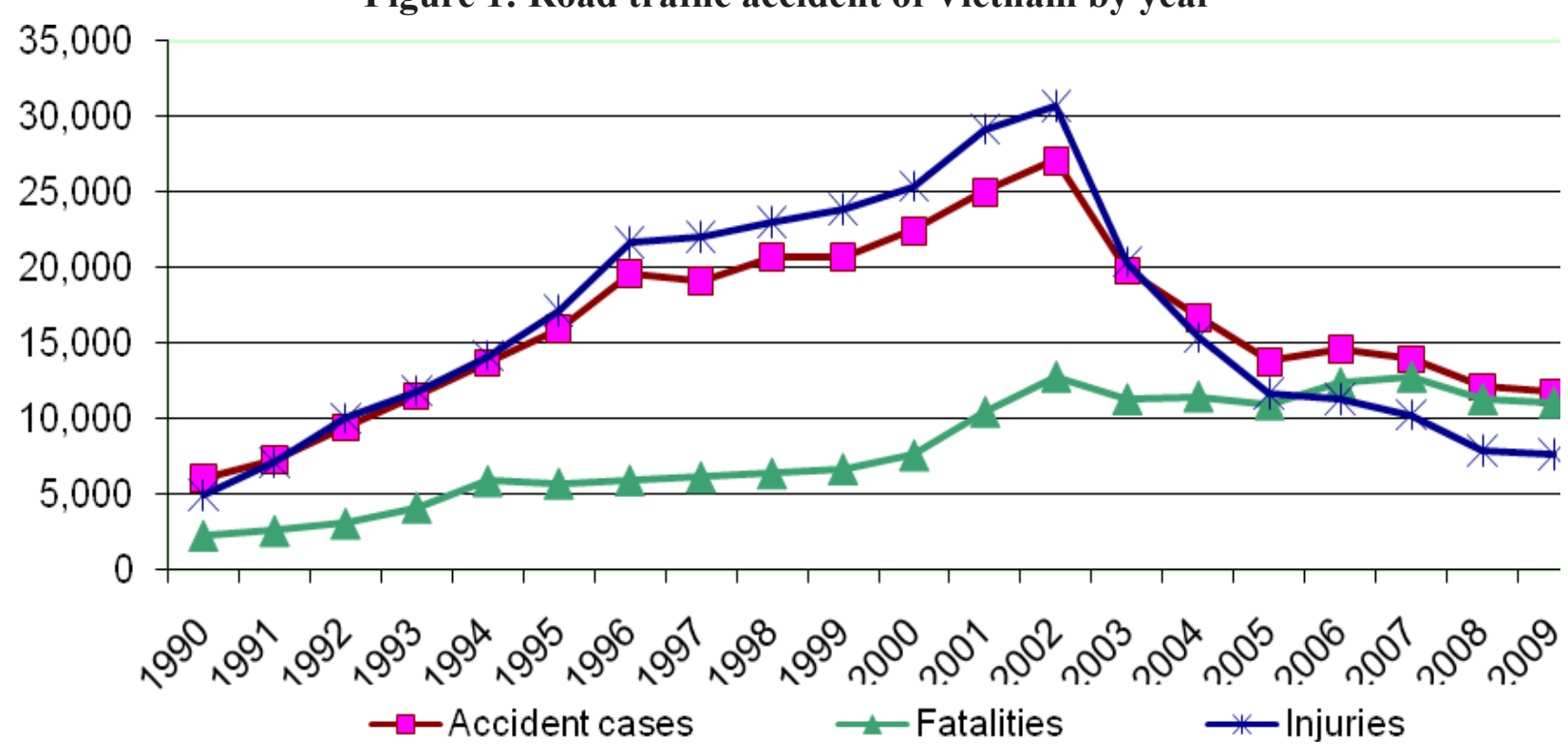

Source: National Traffic Safety Committee

\footnotetext{
${ }^{1}$ Ho Chi Minh City Open University
} 
Figure 2 and Figure 3 show the fact of road safety in the two major cities of Vietnam: Hanoi and Ho Chi Minh City. The number of accidents and injuries is reduced

\section{Figure 2: Road traffic accident of Hanoi}

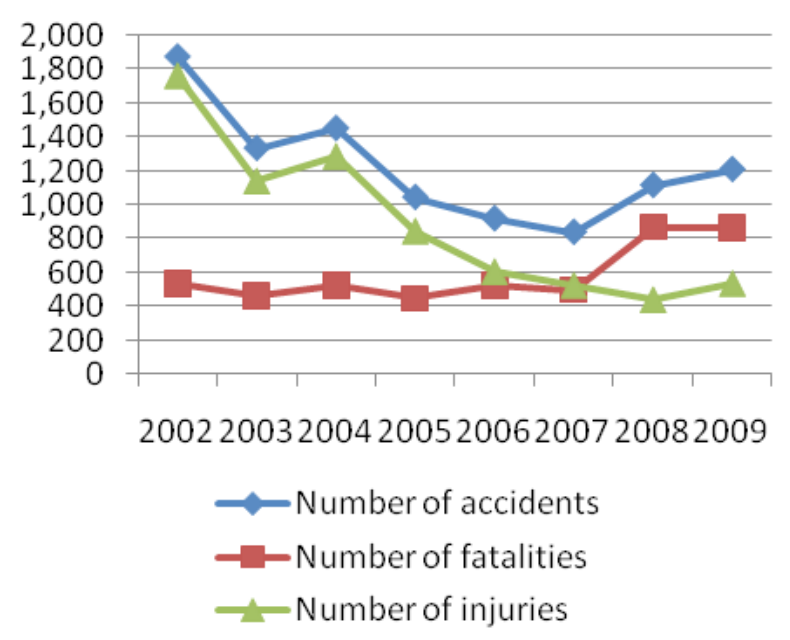

Most of road accidents were caused by motorcycle $(70 \%$ among the total). It is revealed that severity of traffic accidents is the problem, especially for motorcycle transport mode, 50\% among the traffic accidents were traumatic brain injury (TBI) and the rate of heavy injury and fatal was 25\%. From 2007, the Government forced people to wear helmet, then some positive signal appeared as a result, however, a small change could not convince the improvement trend of road traffic.

For the short time, the number of TBI has been reduced $20 \%$ - 50\% compared to that of before; and the rate of death due to road crash reduced to $15 \%$. However, from the end of year 2008, the number of fatalities was increasing; the number of TBI was jumping up as before.

\section{Helmet Usage of Motorcycle Drivers and Passengers}

The survey is taken with totally 1038 samples, 517 samples in Hanoi and 521 samples in Ho Chi Minh City. Place of survey allocated at 15 districts, 9 districts in Ho Chi Minh City and 5 districts in Hanoi (detail shown in Appendix 1, Table A). up to 2007, and then slightly increased; however, the number of fatalities is increased by year.

\section{Figure 3: Road traffic accident of HCMC}

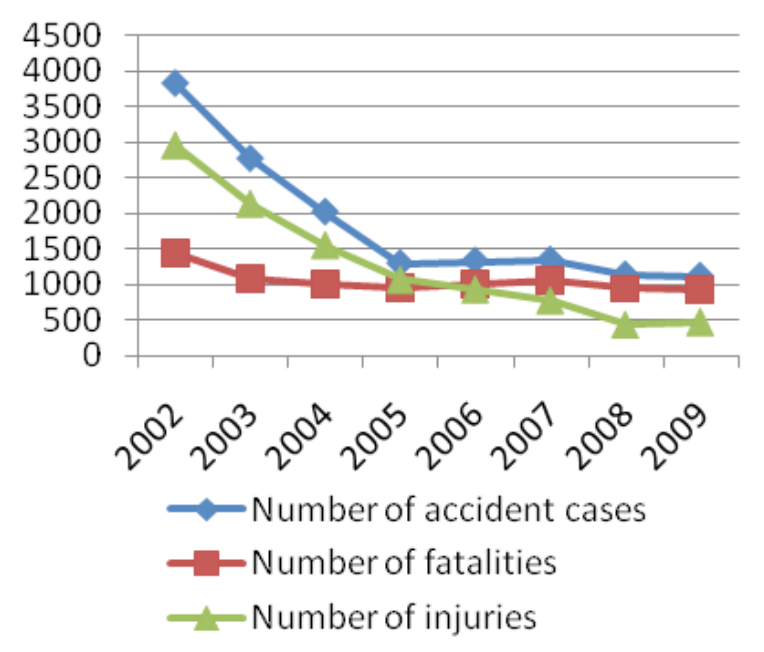

\section{Feature of the interviewees}

The survey result shows that 56\% of interviewees were female; most of interviewees were the youth $(65 \%$ of the total were under 35 years old) and well educated (60\% among the total were educated at the university (Appendix 2, Table B).

Asking about their motorcycle, $89 \%$ of interviewees owned theirmotorcycle; most of those were less than $100 \mathrm{cc}(76 \%)$ compared with $23 \%$ of them being larger than $100 \mathrm{cc}$ but less than $500 \mathrm{cc}$. $87 \%$ of interviewees were drivers and many of them going alone (80\%); $75 \%$ of interviewees were traveling to/from work (or to schooling) (see Appendix 2, Figure A, B, C, D).

\section{Helmet usage of motorcycle drivers and passengers}

Almost all of the interviewees own their helmets (98\%) due to the regulation from the Government to force people to wear helmet when driving on the road. $36 \%$ of the interviewees bought helmets in the helmet shop, while around 24\% bought at street market, 18\% bought from shopping centre, shown more detail in figure 4 . The number of people who were given helmets or bought them through suggestion of $\mathrm{f}, \mathrm{c}$, a is smaller. 
Figure 4. The place to purchase helmet

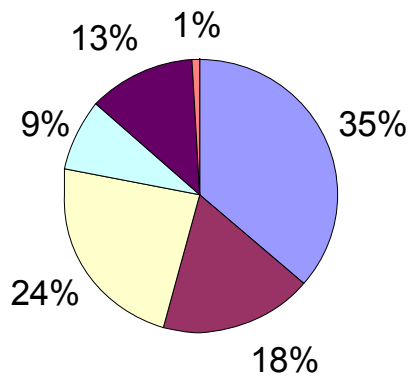

$$
\begin{aligned}
& \square \text { HelmetShop } \\
& \square \text { Shopping Center } \\
& \square \text { Street market } \\
& \square \text { Friend, colleague, acquaintance } \\
& \square \text { Given } \\
& \square \text { Found }
\end{aligned}
$$

Asking about the cost of helmets, it is found that most of people bought helmets with the price from 5 to 10 US\$ (37\% of the interviewees) and between $11-20$ US\$
( $45 \%$ of the interviewee); while very few (3\%) bought helmets with the price over 20 US\$. Figure 5 shows the result.

Figure 5. The cost of helmets

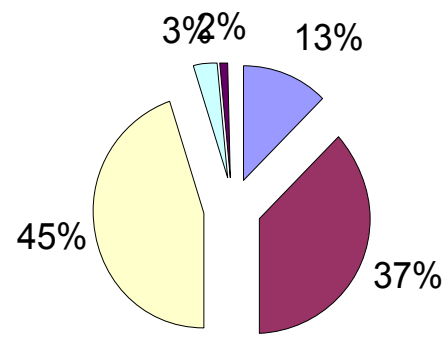

Asking the factors that affect to people's decision to buy helmets, Figure 6 showed that most of people said they bought the helmets due to it was certified as a "standard" helmet (28\%); while very few

$$
\begin{aligned}
& \square \text { less than US } \$ 5 \\
& \square \text { US } \$ 5 \text { - less than } \$ 10 \\
& \square \text { US } \$ 10 \text { - less than } \$ 20 \\
& \square \text { US } \$ 20 \text { or more } \\
& \square \text { Don't know }
\end{aligned}
$$

(7\%) bought due to theirs price, style/look or quality. Noted that $55 \%$ of the interviewees said they bought helmets due to all of the reasons above.

Figure 6. Factors affected purchase decision

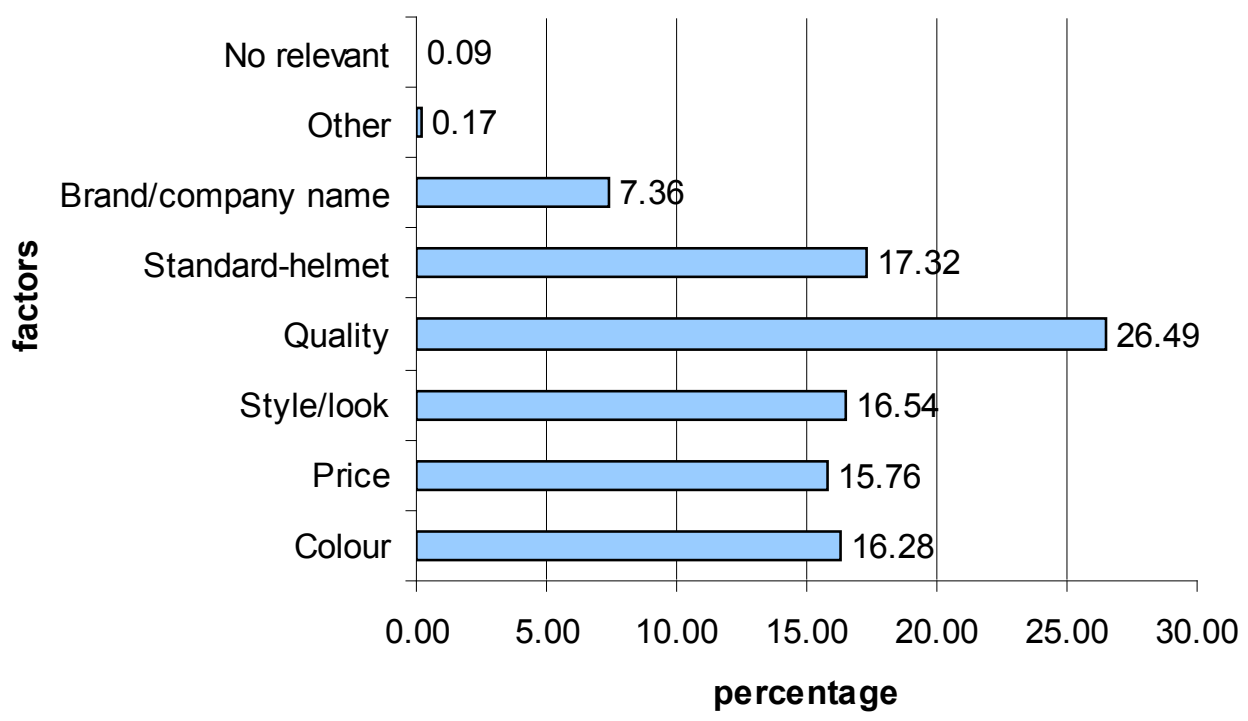

\section{Standard motorcycle helmet usage}

For the interviewer's observation of a certification marking/sticker in the helmet, it is proved that $89 \%$ of the observed helmets had certification marking/stickers and 11\% the remains had none. The interviewers noted that $90 \%$ of observed certification marking/stickers in the helmet are authentic certification marking/stickers. With "a standard helmet" question of the observed 
interviewers, almost agree that the observed helmets are standard (78\%) (more details were given in Appendix 3, Table C, D).

For the considered reason of non standard helmet, while $9 \%$ of motorcycle helmets were without certificate stickers; $5 \%$ of motorcycle helmets were construction helmets, horse-riding hats or hats normally designed/used for other purposes or cracked or damaged (Figure 7).

Figure 7. The reason that the interviewer consider helmet were non-standard

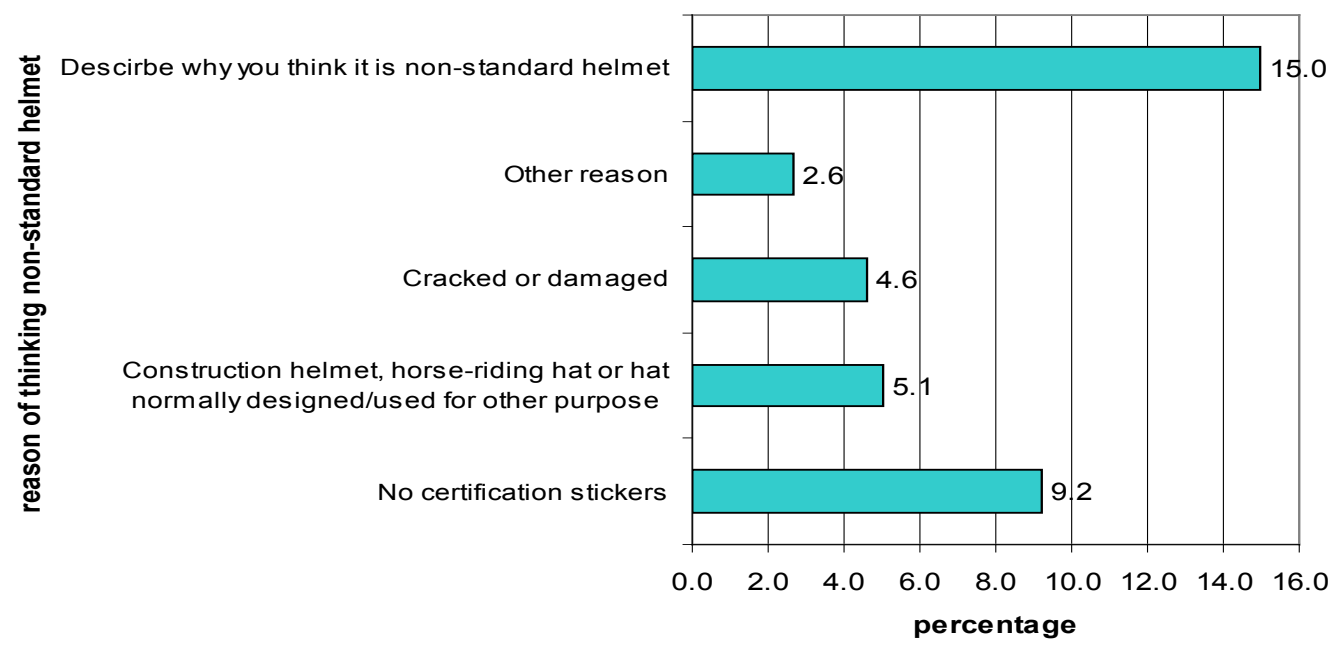

Integrated comparative of helmet usage between Hanoi and Ho Chi Minh City

The place to buy helmet between Hanoi and Ho Chi Minh City of respondents is shown more details in Appendix 4, the Hanoi people prefer to buy helmets in street market (17\%) while Ho Chi Minh city people like to buy helmets at helmet shop $(25 \%)$.

The price to buy helmet between Hanoi and Ho Chi Minh City of respondents is different. The Hanoi people prefer to buy helmets with the price between 10-20 US\$ (30\%) while Ho Chi Minh city people prefer the lower price, between $5-10$ US\$ (21\%) (see Appendix 4, Table F).

The factors that affect people to buy helmets between Hanoi and Ho Chi Minh City are also a little bit different. The Hanoi people prefer to buy them due to theirs color $(23 \%)$, which is higher than that in Ho Chi Minh city (see Appendix 4 , Table G). Some people who could buy helmets at the price more than 20USD consider much all given reasons (color, style/look, quality, standard) while most of people who could buy helmets at the price from 5-20 USD consider the color as the most important thing, and less significant factor is quality of the helmet.

There was the relationship between the age of respondents and the price of helmets. Even the trend is that people getting older would buy helmets with higher price, however, the difference is not much (Appendix 4, Table H). Data also showed the trend of people getting older would use more standard helmets as a relationship between the age of respondents and their usage of standard helmets (Appendix 4, Table J).

Data also showed the relationship between sex of respondents and their usage of standard helmets: male use standard helmets a little bit more than female (Appendix 4, Table K).

\section{Helmet Market}

The market survey was be conducted in the two biggest cities of Vietnam with totally 25 retail outlets including 58\% in Hanoi and $42 \%$ in Ho Chi Minh City (Detail showed in Appendix 5). Helmet market in Vietnam is diversified; there were $42 \%$ and $25 \%$ of helmets sold in the general shop or supermarket and helmet shop only. 
There was a big difference from the cost level for standard helmets in each type of helmet and helmet manufacturer, meaning that was a big gap between lowest price and highest price. The most common price of standard helmets was range from 6 USD to 14 USD (47\%). The most expensive price of standard helmet is $14-25$ USD (39\%) and over 25 USD (18\%). While the most price of non-standard helmets $(83 \%)$ was under 6 USD.

Table 1 shows data of helmet market. Buying a helmet with price under 6 USD could receive a standard helmet with the probability of $25 \%$, however, probability to have non-standard one is higher $(75 \%)$. Buying a helmet with one price range in (6 - 14 USD) could get a standard helmet with high probability (91\%), and even small probability of non-standard helmet (9\%). For sure the helmet with price over 14 USD is the standard helmet.

The price of non-standard helmets in Hanoi is lower than HCMC while the price of standard helmets in HCMC is lower than that in Hanoi (see Appendix 5, Table $\mathrm{M}, \mathrm{N}, \mathrm{O})$.

Table 1

Standard helmets and non-standard helmets by prices

\begin{tabular}{|l|r|r|r|r|r|r|}
\hline & \multicolumn{3}{|c|}{ Standard helmets } & \multicolumn{3}{c|}{ Non-standards helmet } \\
\hline & Low price & $\begin{array}{c}\text { Normal } \\
\text { price }\end{array}$ & $\begin{array}{c}\text { High } \\
\text { price }\end{array}$ & Low price & $\begin{array}{c}\text { Normal } \\
\text { price }\end{array}$ & $\begin{array}{c}\text { High } \\
\text { price }\end{array}$ \\
\hline$<6$ USD & 0.26 & & & 0.30 & 0.26 & 0.19 \\
\hline $6-14$ USD & 0.49 & 0.40 & 0.02 & & 0.02 & 0.07 \\
\hline $14-19$ USD & & 0.67 & 0.33 & & & \\
\hline $19-25$ USD & & 0.27 & 0.73 & & & \\
\hline$>25$ USD & & & 1.00 & & & \\
\hline
\end{tabular}

IV. Survey on Traffic Accidents from

\section{Hospital Side}

\section{Traffic accidents and helmet usage}

Traumatic brain injury (TBI) occurs when an outside force traumatically injures the brain. TBI can be classified based on severity, mechanism (closed or penetrating head injury), or other features (e.g. occurring in a specific location or over a widespread area). TBI is a major cause of death and disability worldwide, especially in children and young adults. Causes include falls, vehicle accidents, and violence. For traffic accidents, prevention measures include use of technology to protect those who are in accidents, such as seat belts and or motorcycle helmets, as well as efforts to reduce the number of accidents, such as safety education programs and enforcement of traffic laws.
The interview survey was taken to doctors at the Choray Hospital (the hospital for physical injuries) and HCMC Traumatic and Reform Hospital to identify the problem of helmet usage and road traffic accidents in the two major cities of Vietnam. According to the survey, the number of traffic accidents in the hospital occupied $1 / 2$ of total cases there. Among traffic accident cases, a half among the total were physical break injuries and a half were traumatic brain injuries in half which $1 / 2$ of those were non-helmet using cases and the left $1 / 2$ were non-standard helmet using or wear on the wrong ways.

Helmet usage, TBI trend to reduce in the short time and increase after that

After forcing people to wear helmet in 2007 , for the short time, the number of TBI has been reduced 20\% - 50\% compared to that of before. In Choray Hospital, the 
outstanding hospital on physical injuries, in many cases, the injuries were serious; however, the head was more protected by helmet wearing. However, from the end of year 2008 up to present, traffic accidents with TBI were jumped up as before. 50\% among the traffic accidents were TBI. Then serious level also increased, during that time, the heavy disease and fatal rate due to TBI was $25 \%$, reduced to $15 \%$ when the Government started to enforce people to wear helmet, and now the rate is increasing at $25 \%$.

\section{Non-standard helmet usage or by a wrong way}

Data from the interview survey show that, in many cases, motorcycle drivers wear non-standard helmet and or in wrong ways, then the accident would be heavy and the victim would be TBI. In case of using standard helmet, even the helmet was broken or failed, the victims avoid from TBI. The doctor said about the important of standard type of helmets, and the right way of usage.

Data from the National Traffic Safety Committee shows almost 99\% of motorcyclists in the inner cities has used helmets. However, in the suburban areas, people wear helmets to deal with traffic police, then most of them wear helmets in the wrong ways.

In many cases, people who used fashion helmets or plastic brim helmets could have serious injured in head, eyes, scruff and neck when crash happening. For non-standard helmets, the sponge could not absorb and the cover could not dispose the press of crashing then heavy injury could be happened.

Many fashion helmets which are under standard are selling in the market. Those helmets could not protect people when crashing, even causes serious injury for them. According to the data from Technical Measurement Standard Center and Traffic Police Office, there are 17 TBI cases due to non-standard usage in only half of March 2009.

The form, style and size of helmets also have problems. The half-head helmets that are using by many motorcyclist are appropriate to travel around the inner city with a slow speech (around $30 \mathrm{~km} / \mathrm{h}$ ). If crash occurred, they would not suffer heavy injury. Most of victims of TBI due to road crash are wearing half-head helmets when driving high speed in highway. The full face helmet should be the best choice for people driving motorcycle on the highway for their safety. The young people like fashion styles which look more beautiful and colorful, however, those are under standard and could not help people avoid TBI from crashing. Many nonstandard ones with un-clear information about the name, origin, manufacture, date... are distributed widely in the market. Those helmets could bring many potential dangers for people using them.

Motorcyclists wearing helmets in a wrong ways such as non fasten, loose fasten, helmet size bigger than the head... could be heavily injured from road crash.

\section{Helmets for the kids}

Road accidents of the kids are increased during the time. Not wearing helmets when the kids going with their parents is prevailing. Moreover, in some cases the kids wearing non-standard helmets and or in the wrong ways could have the same problem as analyzed earlier.

Survey that was taken in Kid Hospital 2 revealed that $60 \%$ of the kids coming to the hospital were related to TBI due to road crashes. From August 2008 to July 2009, there were 43 kids under 15 years old with TBI and $63 \%$ of them due to road crashes.

\section{Regulation and Enforcement}

There is the legislation in Vietnam about the standard of motorcycle helmets. By that regulation, the manufacture, the import, the sale and the use of non-standard 
helmets are not allowed. However, financial punishment is still lacking. Data of offences or convictions for the manufacture and the use of non-standard helmets are not available while there are some records for the import and the sale of non-standard helmets in Hanoi.

Therefore, in order to improve road safety, the Government to have enforcement with punishment solution and to strictly deal with the manufacture, the import, the distribution and the use of non-standard helmets. The Market Management Unit is required to enhance inspection and control to discover non-standard helmets. Mass media have to do campaign and propagation for people to use standard helmets and impacts of using non-standard helmets.

Appendix 6 showed the specific documents relating to regulation and enforcement of using standard helmet in Vietnam

\section{Conclusion}

In this paper, five specific surveys were taken to reveal the problem. The first survey was taken to 1038 motorcycle users to identify the use of helmets including type, price, place to buy, people's features and reason of using standard or nonstandard helmets including five factors price, type, color and form, brand, quality. Therefore it was reaved that most of people use non-standard helmets even those have certification stamp. The second survey was taken at the helmet market and then revealed that many helmets sold in the market were non-standard. The third survey toward 5 hospitals in the two cities and revealed that the number of traffic accident into the hospital occupied $1 / 2$ of total cases there. Among traffic accident cases, a half among the total were physical break injuries and a half were traumatic brain injuries in which $1 / 2$ of those were non-helmet using cases and the left $1 / 2$ were non-standard helmets using or wearing on the wrong ways. Data show in many cases, motorcycle drivers wear non-standard helmet and or in wrong ways, then the accidents would be heavy and the victims would suffer TBI. The fourth survey was taken to analyze the problem of helmet for kids. The fifth survey 9 traffic safety agencies.

Based on the road traffic safety in the major two cities of Vietnam, enforcement and education are very important to improve the situation. To improve road traffic safety in Vietnam, changing people's attitude and awareness is very important and needs to be dealt firstly.

\section{References}

Data from Protect Helmet Enterprise, Traffic Police Team of Hadong, Hanoi City, National Traffic Safety Committee, Directorate for Standards and Quality, Ministry of Science and Technology, Traffic Police Office of Ho Chi Minh City, Market Management Unit of Ho Chi Minh City, Ho Chi Minh City Custom Department, Department of Science and Technology, Ho Chi Minh City.

The "National technical regulation on protective helmets for motorcycle and moped users" (QCVN 2: 2008/ BKHCN).

Using Helmet: Road Traffic Safety Manual for Planning and Implementation. WHO. 2006

Helmet use saves lives. WHO. 2009

PrevalenceofHelmetuseAmong Motorcycle Riders in Vietnam. D V Hung, M R Stevenson, R Q Ivers. 2006

\section{Appendix}




\section{Appendix 1}

Table A: Place of survey

\begin{tabular}{|c|c|c|}
\hline Place & Frequency & Valid Percent \\
\hline Petrol station in Tran Hung Dao road, Dist. 1, HCMC & 25 & 4.65 \\
\hline Petrol station in Cach Mang Thang Tam road, Dist. 3, HCMC & 25 & 4.65 \\
\hline Petrol station in Ben Van Don street, Dist. 4, HCMC & 51 & 9.48 \\
\hline Petrol station in Nguyen Trai road, Dist. 5, HCMC & 50 & 9.29 \\
\hline Petrol station in Le Van Viet road, Dist.9, HCMC & 44 & 8.18 \\
\hline Petrol station in Vo Van Ngan road, Dist.Thuduc, HCMC & 6 & 1.12 \\
\hline Petrol station in Hoang Van Thu road, Dist.Tanbinh, HCMC & 47 & 8.74 \\
\hline Petrol station in An Suong Bus Station, Dist.Hocmon, HCMC & 16 & 2.97 \\
\hline Petrol station in Tan Ky Tan Quy road, Dist. Tanphu, HCMC & 6 & 1.12 \\
\hline Petrol station in Hoang Quoc Viet road, Dist. Tayho, HN & 50 & 9.29 \\
\hline Petrol station in Tay Son road (Nam Dong station), Dist. Dongda, HN & 50 & 9.29 \\
\hline Petrol station in Bach Mai road, Dist. Haibatrung, HN & 53 & 9.85 \\
\hline Petrol station in Nguyen Trai road, Dist. Thanhxuan, HN & 50 & 9.29 \\
\hline Petrol station in Hadong Bus Station, Dist. Hadong, HN & 50 & 9.29 \\
\hline Petrol station in Tran Hung Dao road, Dist. Hoankiem, HN & 15 & 2.79 \\
\hline Total & 538 & 100.00 \\
\hline
\end{tabular}

\section{Appendix 2}

Table B. Percentage of people who own motorcycles.

\begin{tabular}{|l|r|r|}
\hline Own motorcycle & Frequency & \multicolumn{1}{|c|}{ Valid Percent } \\
\hline Yes & 474 & 88.60 \\
\hline No & 61 & 11.40 \\
\hline Total & 535 & 100.00 \\
\hline
\end{tabular}

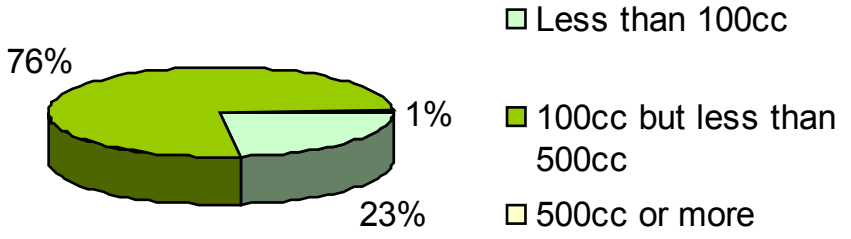




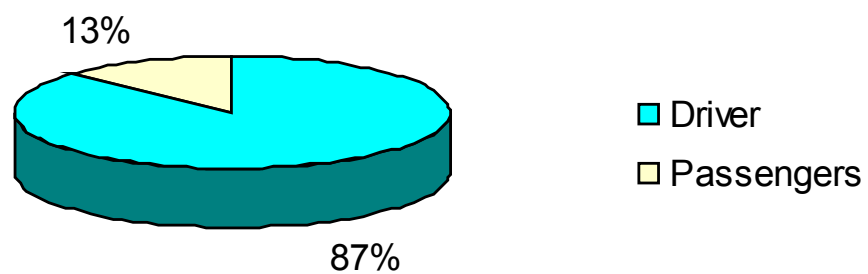

Figure B. Status of motorcyclist

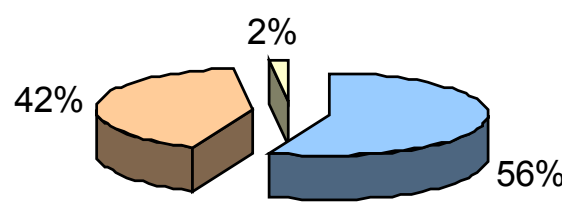

$\square$ One person

$\square$ Two people

$\square$ More than two

persons

Figure C. Number of person of the motorcycle

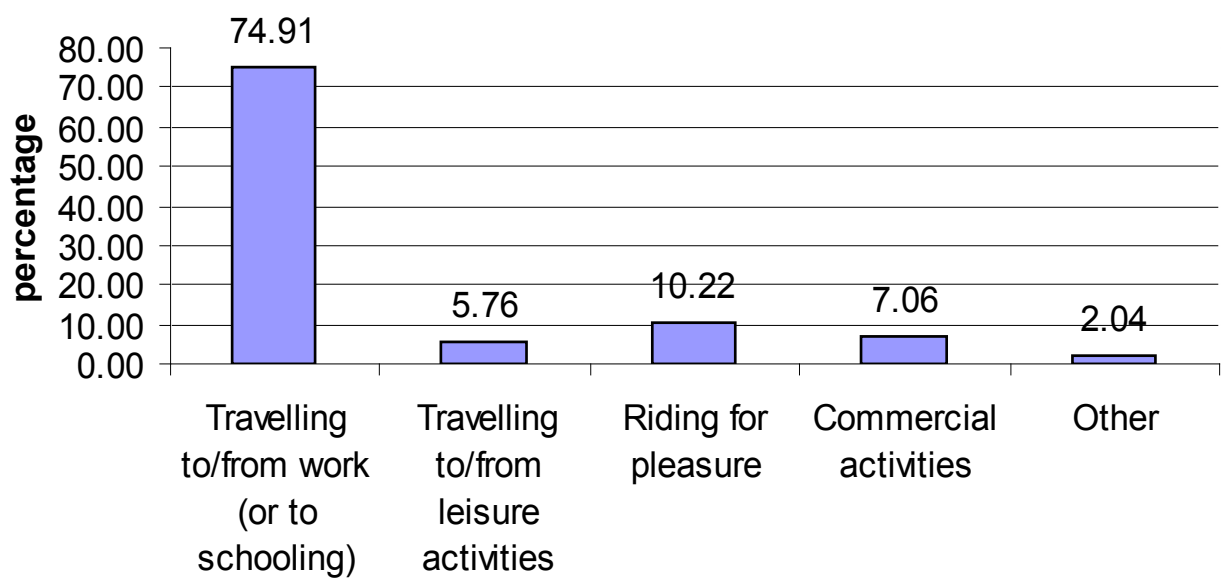

trip aim

Figure D. The purpose of the trip

\section{Appendix 3}

Table C. Observation of helmet sticker

\begin{tabular}{|l|r|r|}
\hline $\begin{array}{l}\text { Observation of } \\
\text { helmet sticker }\end{array}$ & Frequency & \multicolumn{1}{|c|}{$\begin{array}{c}\text { Valid } \\
\text { Percent }\end{array}$} \\
\hline Yes & 475 & 88.29 \\
\hline No & 62 & 11.52 \\
\hline Missing & 1 & 0.19 \\
\hline Total & 538 & 100.00 \\
\hline
\end{tabular}

Table D. Observation of real sticker

\begin{tabular}{|l|r|r|}
\hline $\begin{array}{l}\text { Observation of real } \\
\text { sticker }\end{array}$ & Frequency & \multicolumn{1}{c|}{$\begin{array}{c}\text { Valid } \\
\text { Percent }\end{array}$} \\
\hline Yes & 435 & 90.44 \\
\hline No & 46 & 9.56 \\
\hline Total & 481 & 100.00 \\
\hline
\end{tabular}




\section{Appendix 4}

Table E. Place to buy helmet (analyzing by survey area)

\begin{tabular}{|c|c|c|c|c|c|c|c|}
\hline \multirow{2}{*}{$\begin{array}{c}\text { The survey } \\
\text { area }\end{array}$} & \multicolumn{6}{|c|}{ The place to buy Helmet (\%) } & \multirow[b]{2}{*}{ Tota } \\
\hline & $\begin{array}{c}\text { Helmet } \\
\text { Shop }\end{array}$ & $\begin{array}{c}\text { Shopping } \\
\text { Center }\end{array}$ & $\begin{array}{l}\text { Street } \\
\text { market }\end{array}$ & $\begin{array}{c}\text { Friend, } \\
\text { colleague, } \\
\text { acquaintance }\end{array}$ & $\begin{array}{l}\text { Bought } \\
\text { from Other }\end{array}$ & Given & \\
\hline Hanoi & 11.45 & 11.07 & 16.41 & 7.25 & 4.77 & 0.19 & 51.15 \\
\hline HCMC & 24.81 & 6.49 & 7.63 & 1.34 & 7.82 & 0.76 & 48.85 \\
\hline Total & 36.26 & 17.56 & 24.05 & 8.59 & 12.60 & 0.95 & 100.00 \\
\hline
\end{tabular}

Table F. Price to buy helmet (analyzing by survey area)

\begin{tabular}{|l|l|l|l|l|l|l|}
\hline \multirow{2}{*}{ City } & \multicolumn{5}{|c|}{ Price of helmet (\%) } & \multirow{2}{*}{ Total } \\
\cline { 2 - 6 } & $\begin{array}{c}\text { less than } \\
\text { US\$ } 5\end{array}$ & $\begin{array}{c}\text { US } \$ 5-\text { less } \\
\text { than } \$ 10\end{array}$ & $\begin{array}{c}\text { US\$ } 10-\text { less } \\
\text { than \$20 }\end{array}$ & $\begin{array}{c}\text { US\$ } 20 \text { or } \\
\text { more }\end{array}$ & Don’t know & \\
\hline Hanoi & 5.25 & 16.63 & 29.98 & 1.53 & 0.00 & 53.39 \\
\hline HCMC & 7.44 & 20.57 & 15.54 & 1.31 & 1.75 & 46.61 \\
\hline Total & 12.69 & 37.20 & 45.51 & 2.84 & 1.75 & 100.00 \\
\hline
\end{tabular}

Table G. Factors that affect people to buy helmet (analyzing by survey area)

\begin{tabular}{|c|c|c|c|c|c|c|c|c|c|}
\hline \multirow[b]{2}{*}{ City } & \multicolumn{8}{|c|}{ Factors affect people's decision to buy helmet (\%) } & \multirow{2}{*}{ Tota } \\
\hline & Color & Price & $\begin{array}{l}\text { Style/ } \\
\text { look }\end{array}$ & Quality & $\begin{array}{c}\text { Standard- } \\
\text { helmet }\end{array}$ & $\begin{array}{c}\text { Brand/ } \\
\text { company } \\
\text { name }\end{array}$ & Other & $\begin{array}{c}\text { No } \\
\text { relevant }\end{array}$ & \\
\hline Hanoi & 22.39 & 8.26 & 6.96 & 10.22 & 5.22 & 0.00 & 0.00 & 0.00 & 53.04 \\
\hline TpHCM & 18.48 & 8.48 & 1.96 & 11.96 & 5.22 & 0.43 & 0.22 & 0.22 & 46.96 \\
\hline Total & 40.87 & 16.74 & 8.91 & 22.17 & 10.43 & 0.43 & 0.22 & 0.22 & 100.00 \\
\hline
\end{tabular}

Table $H$. The relationship between the age of respondent and the price of helmet

\begin{tabular}{|c|c|c|c|c|c|c|}
\hline \multirow[b]{2}{*}{ Age } & \multicolumn{5}{|c|}{ Price of helmet (\%) } & \multirow[b]{2}{*}{ Total } \\
\hline & $\begin{array}{c}\text { less than } \\
\text { US\$ } 5\end{array}$ & $\begin{array}{c}\text { US\$ } 5 \text { - less } \\
\text { than } \$ 10\end{array}$ & $\begin{array}{c}\text { US\$ } 10- \\
\text { less than } \\
\$ 20\end{array}$ & $\begin{array}{l}\text { US\$ } 20 \text { or } \\
\text { more }\end{array}$ & Don’t know & \\
\hline 18-23year-old & 15.12 & 34.88 & 43.02 & 4.65 & 2.33 & 100.00 \\
\hline 24-35year-old & 10.75 & 41.59 & 43.93 & 2.34 & 1.40 & 100.00 \\
\hline Over 36year-old & 14.19 & 32.90 & 48.39 & 2.58 & 1.94 & 100.00 \\
\hline
\end{tabular}


Table I: Relationship between the price of helmet and factor affected people to purchase helmet

\begin{tabular}{|c|c|c|c|c|c|c|c|c|c|}
\hline \multirow[b]{2}{*}{ Price of helmet } & \multicolumn{8}{|c|}{ Factor $(\%)$} & \multirow[b]{2}{*}{ Total } \\
\hline & Color & Price & $\begin{array}{c}\text { Style/ } \\
\text { look }\end{array}$ & Quality & $\begin{array}{c}\text { Standard } \\
\text {-helmet }\end{array}$ & $\begin{array}{c}\text { Brand/ } \\
\text { company } \\
\text { name }\end{array}$ & Other & $\begin{array}{c}\text { No } \\
\text { relevant }\end{array}$ & \\
\hline less than US\$ 5 & 5.04 & 4.39 & 1.32 & 1.54 & 0.44 & 0.00 & 0.00 & 0.00 & 12.72 \\
\hline US\$ 5 - less than $\$ 10$ & 15.57 & 6.14 & 3.29 & 8.11 & 3.95 & 0.22 & 0.00 & 0.00 & 37.28 \\
\hline US\$10 - less than $\$ 20$ & 19.08 & 6.36 & 3.95 & 10.75 & 5.48 & 0.00 & 0.00 & 0.00 & 45.61 \\
\hline US\$ 20 or more & 1.10 & 0.00 & 0.44 & 0.66 & 0.66 & 0.00 & 0.00 & 0.00 & 2.85 \\
\hline Don't know & 0.44 & 0.00 & 0.00 & 0.66 & 0.00 & 0.00 & 0.22 & 0.22 & 1.54 \\
\hline Total & 41.23 & 16.89 & 8.99 & 21.71 & 10.53 & 0.22 & 0.22 & 0.22 & 100.00 \\
\hline
\end{tabular}

Table $J$. The relationship between the age of respondent and the usage of standard helmet

\begin{tabular}{|c|c|c|c|}
\hline \multirow{2}{*}{ Age } & \multicolumn{2}{|c|}{ Standard Helmet (number) } & \multirow{2}{*}{ Total } \\
\hline & Yes & No & \\
\hline 18-23year-old & 78 & 31 & 109 \\
\hline 24-35year-old & 192 & 48 & 240 \\
\hline Over 36year-old & 141 & 40 & 181 \\
\hline Total & 411 & 119 & 530 \\
\hline
\end{tabular}

Table K. The relationship between sex of respondent and their usage of standard helmet

\begin{tabular}{|l|l|l|l|}
\hline \multirow{2}{*}{ Sex } & \multicolumn{2}{|c|}{ Standard Helmet (number) } & \multirow{2}{*}{ Total } \\
\cline { 2 - 3 } & \multicolumn{2}{|c|}{ Yes } & \multicolumn{2}{c|}{ No } & \\
\hline Male & 232 & 63 & 295 \\
\hline Female & 172 & 54 & 226 \\
\hline Don't know & 10 & 3 & 13 \\
\hline Total & 414 & 120 & 534 \\
\hline
\end{tabular}

Appendix 5

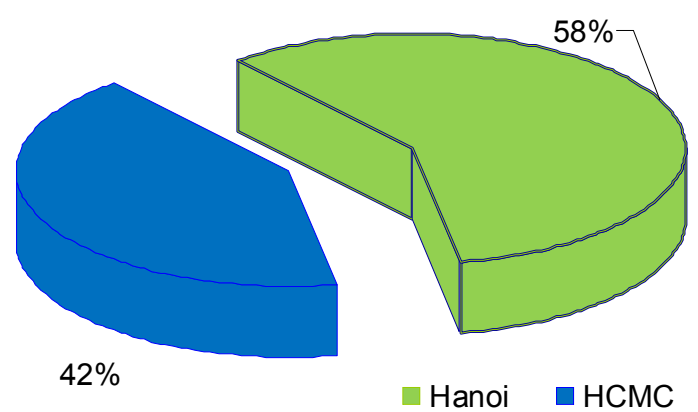

Figure E. The surveyed cities 
Table L. Location of retail outle

\begin{tabular}{|l|l|}
\hline \multicolumn{1}{|c|}{ Location of retail outlet } & \multicolumn{1}{c|}{ Percentage } \\
\hline Chua Boc, Dong Da, HN & 8.3 \\
\hline CMT8, Dis10, HCMC & 25.0 \\
\hline Ha Dong,HN & 33.3 \\
\hline Nguyen Trai, Ha Dong, HN & 8.3 \\
\hline PhamHongThai, Dis1, HCMC & 16.7 \\
\hline Truong Chinh, Dong Da, HN & 8.3 \\
\hline \multicolumn{1}{|c|}{ Total } & 100.0 \\
\hline
\end{tabular}

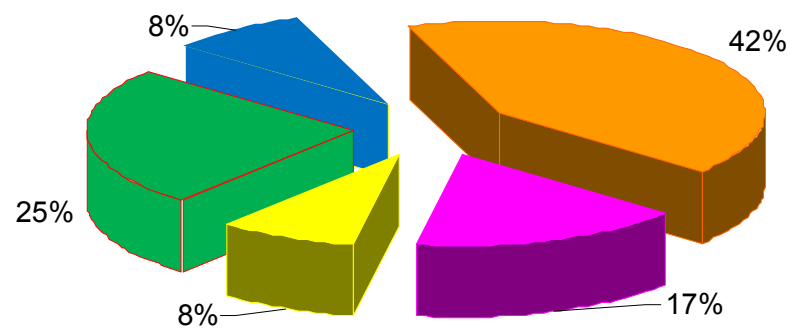

$\square$ General shop or supermarket also selling helmets

- Informal road vendors or little roadside shops selling helmets

Other: selling helmet "Protect" only

n Other: selling helmet only

- Shop selling only automobile or motorcycle and related products

\section{Figure F. Type of retail outlet}

Table M. The cheapest cost for standard helmet

\begin{tabular}{|c|c|c|c|}
\hline \multirow{2}{*}{ Price (USD) } & \multicolumn{2}{|c|}{ City } & \multirow{2}{*}{ Total } \\
\hline & HCMC & Hanoi & \\
\hline \multicolumn{4}{|l|}{ Standard Helmet } \\
\hline 6 & $14.3 \%$ & $28.6 \%$ & $42.9 \%$ \\
\hline 7 & $0 \%$ & $28.6 \%$ & $28.6 \%$ \\
\hline 12 & $0 \%$ & $14.3 \%$ & $14.3 \%$ \\
\hline 26 & $14.3 \%$ & $0 \%$ & $14.3 \%$ \\
\hline Total & $28.6 \%$ & $71.4 \%$ & $100.0 \%$ \\
\hline \multicolumn{4}{|l|}{ Non-standard } \\
\hline 2 & $0 \%$ & $20.0 \%$ & $20.0 \%$ \\
\hline 3 & $0 \%$ & $20.0 \%$ & $20.0 \%$ \\
\hline 5 & $60.0 \%$ & $0 \%$ & $60.0 \%$ \\
\hline Total & $60.0 \%$ & $40.0 \%$ & $100.0 \%$ \\
\hline
\end{tabular}

Table N. The most expensive cost for standard helmet

\begin{tabular}{|c|c|c|}
\hline Price (USD) & Frequency & Percent (\%) \\
\hline $5-10$ & 2 & 17 \\
\hline $11-20$ & 3 & 25 \\
\hline $21-40$ & 5 & 42 \\
\hline$>40$ & 2 & 17 \\
\hline Total & 12 & 100.0 \\
\hline
\end{tabular}


Table $O$. The most common cost for standard and non-standard helmet

\begin{tabular}{|c|c|c|c|}
\hline \multirow{2}{*}{ Price (USD) } & \multicolumn{2}{|c|}{ City } & \multirow{2}{*}{ Total } \\
\hline & HCMC & Hanoi & \\
\hline \multicolumn{4}{|l|}{ Standard Helmet } \\
\hline 7 & $10.0 \%$ & $.0 \%$ & $10.0 \%$ \\
\hline 8 & $10.0 \%$ & $10.0 \%$ & $20.0 \%$ \\
\hline 9 & $20.0 \%$ & $10.0 \%$ & $30.0 \%$ \\
\hline 11 & $.0 \%$ & $20.0 \%$ & $20.0 \%$ \\
\hline 13 & $.0 \%$ & $10.0 \%$ & $10.0 \%$ \\
\hline 14 & $.0 \%$ & $10.0 \%$ & $10.0 \%$ \\
\hline Total & $40.0 \%$ & $60.0 \%$ & $100.0 \%$ \\
\hline \multicolumn{4}{|c|}{ Non-standard Helmet } \\
\hline 5 & & $100.0 \%$ & $100.0 \%$ \\
\hline Total & & $100.0 \%$ & $100.0 \%$ \\
\hline
\end{tabular}

\section{Appendix 6}

1. Data from Protect Helmet Enterprise, Traffic Police Team of Hadong, Hanoi City, National Traffic Safety Committee, Directorate for Standards and Quality, Ministry of Science and Technology, Traffic Police Office of Hochiminh City, Market Management Unit of Hochiminh City, Hochiminh City Custom Department, Department of Science and Technology, Hochiminh City.

2. Regulation No.04/2008/QD-BKHCN dated 28 April 2008 of the Ministry of Science and Technology.

3. The "National Technical Regulation on Protective Helmets for Motorcycle and Moped users" (QCVN 2: 2008/ BKHCN).

4. Product and Goods Quality Law No. 05/2007/QH12 dated 21 November 2007

5. Criterion and Technical Standard Law No.68/2006/QH11 dated 29 June 2006

6. Decree No.126/2005/ND-CP dated 10 October 2005: Regulation on Administrative Punishment of Products and Goods Quality and Assessment
7. Decree No.06/2008/ND-CP dated 16 January 2008: Administrative Punishment of the Sale of Non-standard Products and Goods

8. Decree No.95/2007/ND-CP dated 4 June 2007: Amendment and Supplementation for the No.126.

9. Decree No.179/2004/ND-CP dated 21 October 2004: Regulation of Quality Management of Products and Goods.

10.Decree No.50/2006/QĐ - TTg dated 07 March 2006: List of Products and Goods to Quality Testing

11. DecreeNo.32/2007/NQ-CPdated29 June 2007 by the Prime Minister: Emergency Solutions to Deal with Traffic Accident and Congestion

12.Decree No.146/2007/NQ-CP dated 14 September 2007 by the Prime Minister: Administrative Punishment in Road Transportation.

13.TCVN 6979: 2001 Standard of Motorcycle Helmets for Children.

14. Traffic Law dated 29 June 2001. 